\title{
The Peri-Operative Pain Management of Total Abdominal Hysterectomy Patients at an Academic Hospital
}

\author{
L Dougalli, $^{1,}$ J Van Nugtering ${ }^{1,} \underline{\text { Chetty }}^{2,3}$
}

1. Department of Anaesthesia \& Perioperative Medicine, University of Cape Town, Cape Town, South Africa

2. Department of Anaesthesiology \& Critical Care, Faculty of Medicine \& Health Sciences, Stellenbosch University, Cape Town, South Africa

3. Department of Anaesthesiology, School of Clinical Medicine, University of Witwatersrand, Johannesburg, South Africa

\section{Introduction}

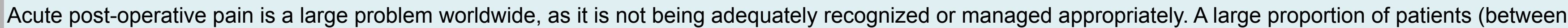

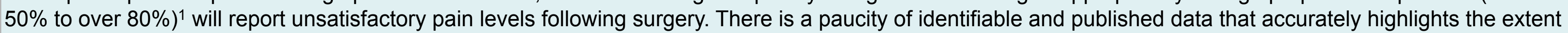
of the problem, in terms of acute postoperative pain management and levels of patient satisfaction, in the South African setting.

Acute pain which is not adequately treated can lead to chronic debilitating pain, which can be both difficult and costly to manage, especially in resource-poor settings ${ }^{2}$. Chronic pain may affect all aspects of a patient's life and have far-reaching consequences ${ }^{3}$. There are many factors which influence the perception of care received by patients 4 ; pain control and medication-related issues are only two small aspects thereof. Some patients in a great deal of pain may still report

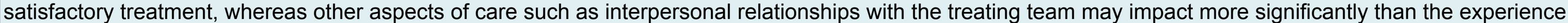
of pain in terms of perception of the quality of care received 5

\section{Aims}

The aim of this study was to describe the peri-operative pain management of Total Abdominal Hysterectomy (TAH) patients at Rahima Moosa Mother and Child Hospital (RMMCH) using the PAIN-OUT Questionnaire.

\section{Methods}

Approval to conduct this study was obtained from the Human Research Ethics Committee of the University of the Witwatersrand.

Patients completed the PAIN OUT patient questionnaire between 6 and 24 hours after surgery. The PAIN OUT process questionnaire was completed at the same time.

A consecutive, convenience sampling method was used to include all post-TAH patients operated on in a three month period at RMMCH.

\section{Results}

Patient Demographics

\begin{tabular}{|l|c|}
\hline Category & No. of Patients \\
\hline Age(years) & 46 (SD8.82) \\
\hline Weight(kg) & 76 (SD15.55) \\
\hline Duration of Surgery(hours) & 1.89 (IQR1.52-2.54) \\
\hline Nationality: & \\
\hline South African (\%) & 87 \\
\hline Other (\%) & 11 \\
\hline Unrecorded (\%) & 2 \\
\hline
\end{tabular}

Intraoperative Analgesia

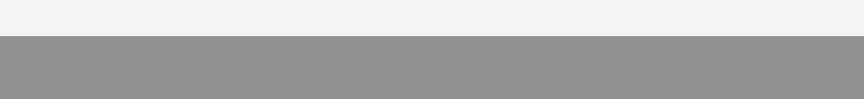

Type of Anaesthetic Used ( $n$ )

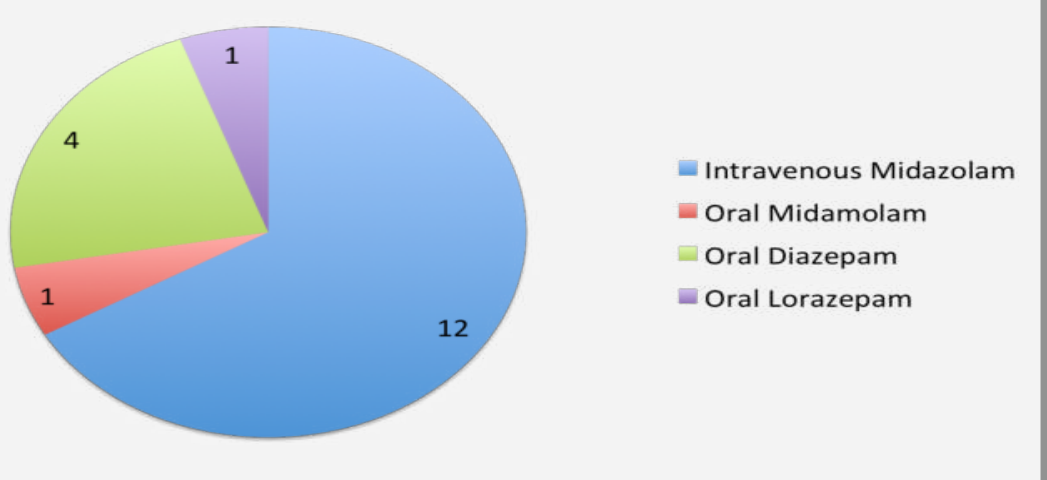

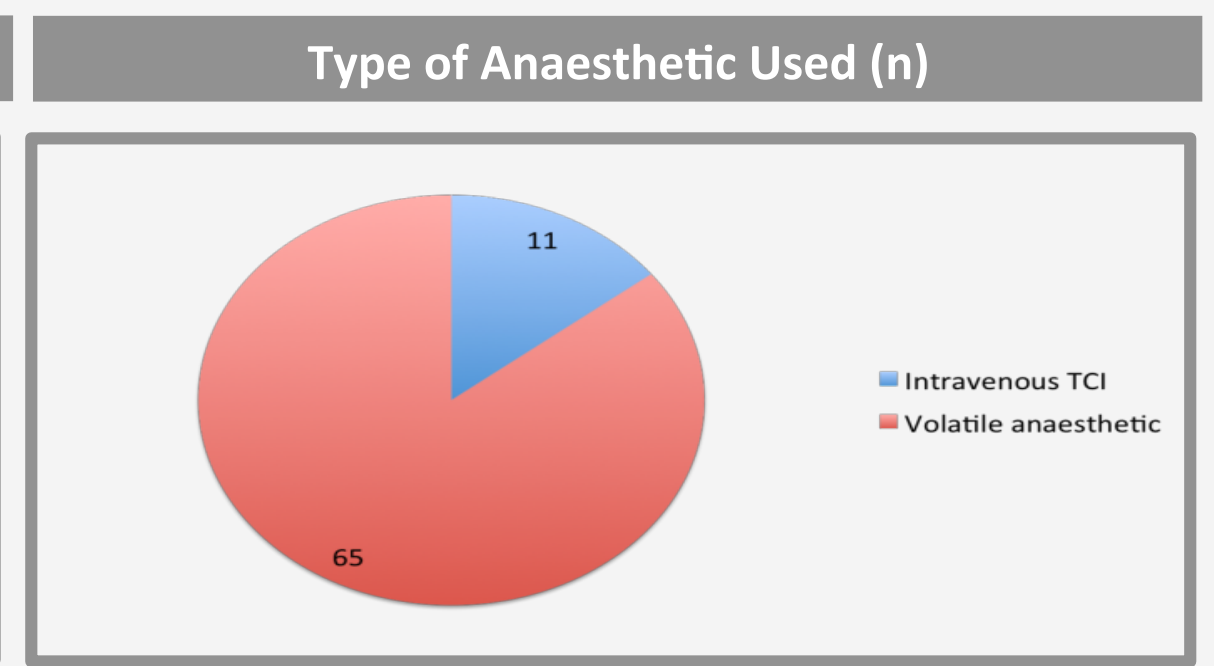

\begin{tabular}{|l|l|}
\hline \multicolumn{2}{|l|}{ Local Anaesthetic Technique Used } \\
\hline TAP Block [n(\%)] & $38(50)$ \\
\hline Wound Infiltration [n(\%)] & $19(25)$ \\
\hline No local anaesthetic [n(\%)] & $19(25)$ \\
\hline
\end{tabular}

\begin{tabular}{|l|l|}
\hline Non-Opioid Medications & \\
\hline Ketamine intravenous bolus $(\mathrm{n})$ & 38 \\
\hline Paracetamol $(1 \mathrm{~g})$ intravenously $(\mathrm{n})$ & 39 \\
\hline Diclofenac $(75 \mathrm{mg})$ intravenously $(\mathrm{n})$ & 4 \\
\hline Diclofenac $(100 \mathrm{mg})$ per rectal suppository $(\mathrm{n})$ & 2 \\
\hline
\end{tabular}

\begin{tabular}{|l|l|}
\hline \multicolumn{2}{|l|}{ Intravenous Opioids Used } \\
\hline Alfentanil (n) & 4 \\
\hline Fentanyl (n) & 42 \\
\hline Sufentanil (n) & 17 \\
\hline Morphine (n) & 73 \\
\hline
\end{tabular}

\section{Post-operative Analgesia in ward}

\begin{tabular}{|l|l|}
\hline Morphine PCA pump (n) & 34 \\
\hline Pethidine intramuscular injection (n) & 29 \\
\hline Oral Tramadol (n) & 5 \\
\hline Morphine intramuscular injection (n) & 18 \\
\hline
\end{tabular}

Post-operative Pain Intensity

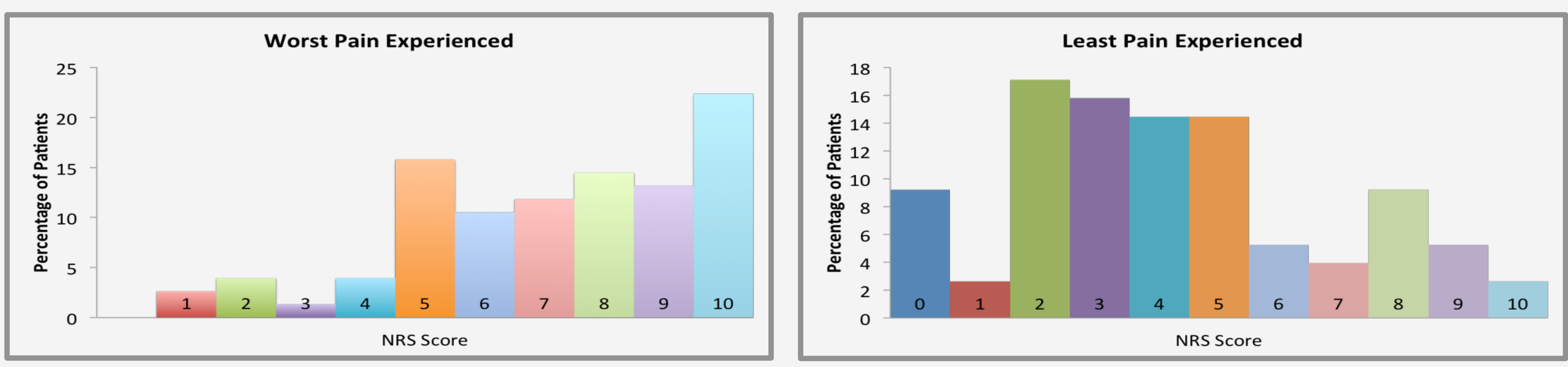

\section{Conclusions}

- There is an unacceptably high level of post-operative pain reported by patients after TAH surgery

- Administration of analgesic medication was not prioritized in the ward prior to the time of patient interview

- An improvement program for post-operative analgesic management for patients having TAH surgery at RMMCH needs to be instituted

- These recommendations are in line with international practice

\section{References}

1. Dolin SJ, Cashman JN, Bland JM. Effectiveness of acute postoperative pain management: I. evidence from published data. BJA Educ. 2002;89(3):409-23.

2. Chetty $S$ et al. Clinical practice guidelines for management of neuropathic pain: expert panel recommendations for South Africa. SAMJ. 2012;100(6).

3. Shipton EA, Tait B. Flagging the pain: preventing the burden of chronic pain by identifying and treating risk factors in acute pain. EJA. $2005 ; 22: 405-12$.

4. Carlson $\mathrm{J}$ et al. Is patient satisfaction a legitimate outcome of pain management? J Pain Symptom Manage. 2003;25(3):264-75.

5. Dawson R et al. Probing the paradox of patient's satisfaction with inadequate pain management. J Pain Symptom Manage. 2002;23(3):211-20. 